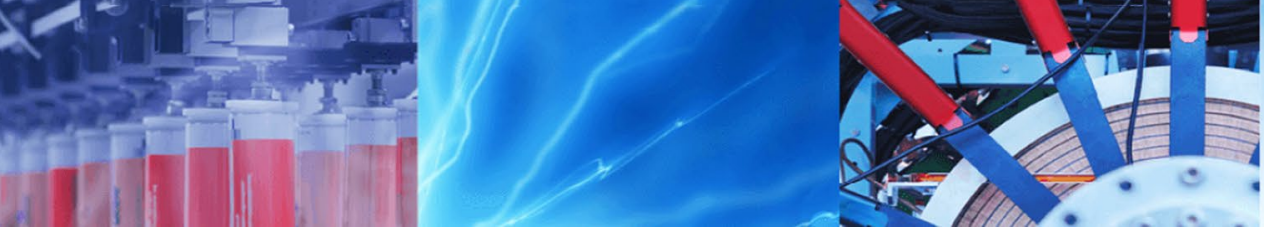

Research Article

\title{
Characterization of Agave americana L. plant as potential source of fibres for composites obtaining
}

\author{
Zaida Ortega $^{1}$ D . Jessica Castellano ${ }^{1} \cdot$ Luis Suárez $^{1} \cdot$ Rubén Paz $^{1} \cdot$ Noelia Díaz $^{1} \cdot$ Antonio N. Benítez $^{2}$. \\ María D. Marrero ${ }^{1}$
}

(c) Springer Nature Switzerland AG 2019

\begin{abstract}
This paper summarises the results obtained from the characterization assays from century plant (Agave americana L.), determining the chemical composition of different parts of the plant. Fibres were obtained by means of a mechanical device, specifically designed and built for Agave americana leaves processing. Obtained fibres were subjected to thermogravimetric analysis and infrared spectra, and their chemical composition was also determined by quantitative acid hydrolysis. Once obtained, fibres were blended up to $40 \%$ (in weight) to obtain composites by compression moulding, using polyethylene as matrix; mechanical testing show improvements in elastic modulus for both tensile and flexural tests; increase in flexural maximum strength were also found for the composites, while tensile strength is slightly reduced with the introduction of agave fibres. The research is part of a project developed in the Macaronesian region, which aim is to demonstrate the feasibility of using biomass from invasive plant species in the composites sector as a way of financing control campaigns and habitats conservation labours, which is the main novelty of this research.
\end{abstract}

Keywords Characterization · Natural fibres · Agave americana L. · Composites · Polyethylene

\section{Introduction}

Invasive species are a thread to the preservation of ecosystems, being their presence especially dangerous in areas with high biodiversity. In particular, some plant species such as giant reed (Arundo donax L.), fountain grass (Pennisetum setaceum), century plant (Agave americana $L$.) or castor oil plant (Ricinus communis) have spread widely in Macaronesia. These plants, among others, are included in the Spanish catalogue of invasive species, produced by the Ministry of Agriculture and Environment [1], and also in the list of invasive plants of the Canary Islands Government [2]; some of them, such as giant reed, are also included in the TOP100 of most dangerous species of the International Union for Conservation of Nature (IUCN) [3]. These plants produce changes in the hydrological regime, compete with endemic species in resources, vary soil conditions (salinity and $\mathrm{pH}$ ) and also contribute to fire propagation, due to the high amount of biomass they produce.

Agave americana $L$. was introduced in Canary Islands in the XVI century, and belongs to the Agavaceae family (also sisal belongs to this family), originally coming from Central America (East of Mexico). This plant leaves from 10 to 30 years and only flowers once in its life. Each plant occupies a space around 1.8-3.0 m, and has green-grey leaves of about $1 \mathrm{~m}$ length, with a prickly margin and a heavy spike at the tip. The plant flower consists in a branched high stalk (up to $9 \mathrm{~m}$ tall), laden with yellow blossoms [2].

EcoFIBRAS project aims at obtaining an updated picture of the current situation of habitats conservation state and the distribution of these species in the Macaronesia region (more specifically in Canary Islands, Madeira and

$\triangle$ Zaida Ortega, zaida.ortega@ulpgc.es | 'Departamento de Ingeniería Mecánica, Universidad de Las Palmas de Gran Canaria, Campus Universitario de Tafira Baja, 35017 Las Palmas, Spain. ${ }^{2}$ Departamento de Ingeniería de Procesos, Universidad de Las Palmas de Gran Canaria, Campus Universitario de Tafira Baja, 35017 Las Palmas, Spain. 
Azores archipelagos), and also in the assessment of their possibilities as reinforcement or fillers of polymers for the production of composites by rotational or compression moulding. It is well known that natural fibres have experienced a great rise in the last years due to their renewable character, low price and high specific properties; moreover, their market is expected to continue registering high growth in the coming years [4]. The increased demand of sisal, ramie and curaua fibres, due to their high mechanical properties is contributing to the market growth. Natural fibres production in 2013 was estimated in 33 million tons, being most of them cotton; other fibres, such as abaca, sisal or flax were produced in about 1.6 million tons; these figures imply a value of about $€ 45$ billion [5]. Natural fibres are used in different sectors, such as pulps for paper, specialty pulp, composites for automotive industry or other sectors, insulation materials, etc. [6].

Agave americana $L$. belongs to the same family as Agave sisalana, and is recognised in the Spanish catalogue of invasive species as an invasive plant in Canary Islands, Basque country and Andalucía [1]. It was first introduced with ornamental purposes and later for the obtaining of bast fibres for textile purposes [7]. Sisal fibres are obtained from Agave sisalana leaves, mainly produced in Mexico (in fact, Mexico practically had the monopoly of sisal fibre production until the beginning of the twentieth century [5]). Most part of sisal fibres used in Europe come nowadays from South Africa, South America and Asia, with a price around $0.56-0.74 € / \mathrm{kg}[6]$.

Some studies have used Agave tequilana to produce bioethanol [8,9], mainly due to its high content in carbohydrates. Saponines obtained from Agave americana were also studied as an additive in animal feeding, effectively increasing lamb growth [10], while others have studied the potential of salts found in Agave americana for fertilizers [11].

Also some references have been found about the extraction of fibres from Agave Americana $L$. leaves for their use in composites production [12-14]. It has been demonstrated that the fibres extraction process greatly influences the properties of the obtained fibres; Bezazi et al. have shown that fibres obtained without water use (by burying the leaves in the ground for 3 months) had better mechanical properties than fibres from water retting [15]. Other authors have used a pectinase solution for fibres obtaining $[16,17]$ or a hydrolysis process followed by leaf calendaring [18]. Traditional process consist in drying the leaves, boiling them (or water retting them) [19] and then removing the non-fibrous materials by squashing leaves [14] or by means of a knife [12]. Mechanical scrapping process is also used for fibres obtained from agave $[20,21]$. Some papers dealing with the fibre extraction from residual bagasse from blue agave (Agave tequilana) can also be found in the literature [22].

The use of fibres obtained from Agave Americana $L$. leaves for composite productions is the strategy followed in the ecoFIBRAS project as a way to give an added value to vegetable residues coming from control campaigns which would be otherwise just burnt or buried in landfills, thus addressing the zero wastes and maximum efficiency in resources use strategies.

\section{Materials and methods}

\subsection{Plant characterization}

Leaves from Agave americana $L$. were cut from wild plants in the area close to ULPGC facilities (campus de Tafira). Figure 1 shows pictures of the plants and leaves.

The leaves were characterized by quantitative acid hydrolysis; Klason lignin was determined following ANSI/ ASTM 1997a [23], while the procedure described by Browning [24] was used to determine the holocellulose content; finally, cellulose was obtained by hydrolysis of holocellulose, following standard procedure shown in ANSI/ASTM 1997b. Glacial acetic acid (from EMSURE), sodium hydroxide (from Honeywell Fluka), sulphuric acid 98\% (from Brenntag Química) and sodium chlorite (from Sigma Aldrich) have been used as reagents for these analyses. For the plant, a total of 450 assays have been conducted, studying 5 different specimens, 6 leaves of each plant, performing 5 replicas for each sample in the different parts of the leaf: entire leaves, pulp and skin.
Fig. 1 Agave americana L. plant (left) and cross-section of a leaf (right)
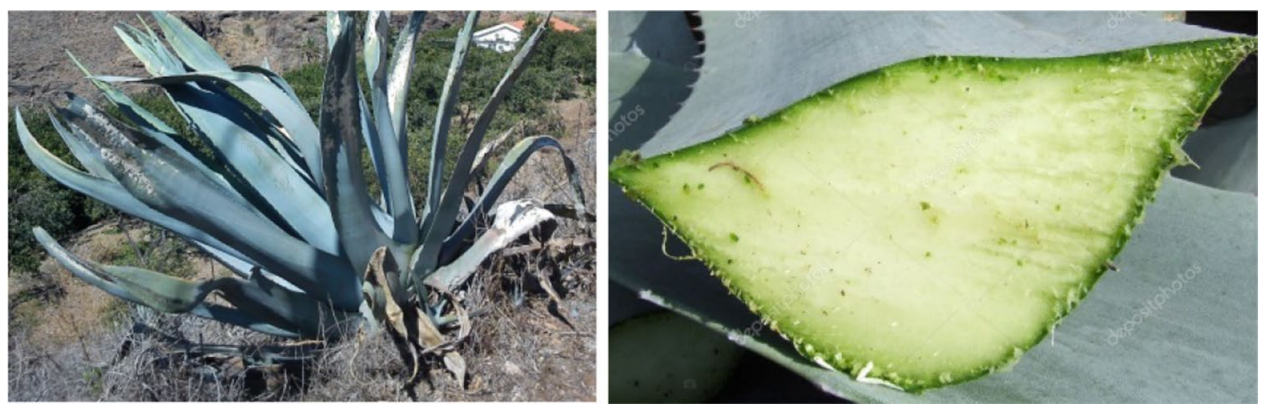


\subsection{Fibre obtaining and characterization}

Fibres were obtained from leaves using a lab-made mechanical device, consisting in a rotatory scraping device (Fig. 2). Each leaf is cut, the sharp edges removed and then fed into the scraping device; the leaf is pulled back and the clean fibres are cut.

Obtained fibres were characterized following the above described procedures to also determine their chemical composition, and were also subjected to thermogravimetric analysis (TGA) and infrared spectroscopy (FTIR). TGA tests were performed in a Mettler Toledo TGA/DSC 1 device, from 25 to $1100^{\circ} \mathrm{C}$ at a heating rate of $5^{\circ} \mathrm{C} / \mathrm{min}$ under nitrogen atmosphere; 9 assays were performed per type of sample. FTIR spectra were obtained in a Perkin Elmer spectrum Two apparatus, equipped with a attenuated total reflectance (ATR) device, from 4000 to $500 \mathrm{~cm}^{-1}$, at a resolution of $16 \mathrm{~cm}^{-1}$, obtaining each spectra as the average of 12 scans; 9 samples were analysed for each sample. The chopped fibres were treated with $\mathrm{NaOH} 1 \mathrm{~N}$ at room temperature for $1 \mathrm{~h}$, followed by washing with distillate water until neutral $\mathrm{pH}$ was achieved; the treated fibre was characterized by the procedures already mentioned. $\mathrm{NaOH}$ treatment is a very common method in literature to reduce hemicellulose $[25,26]$, lignin and other compounds $[19,27]$ in natural fibres, as well as to reduce their hydrophilic character and water absorption $[16,17,27]$.
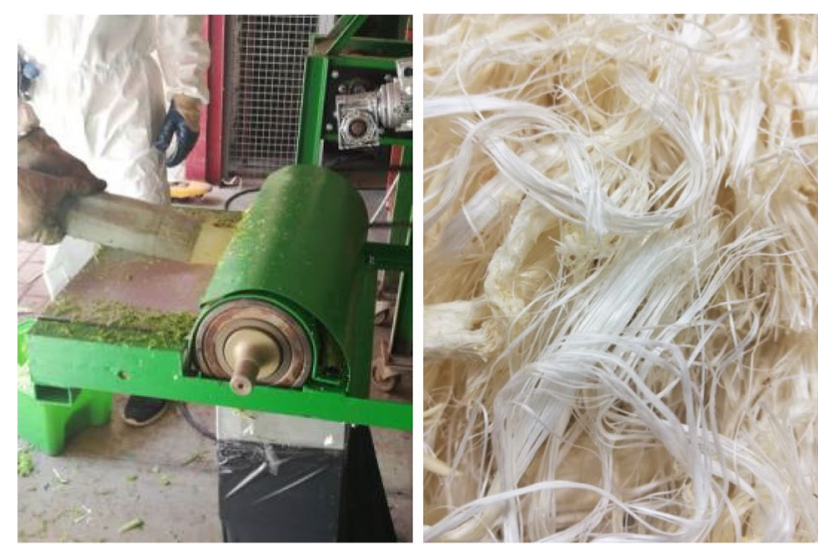

Fig. 2 Device for fibre extraction (left) and obtained fibres (right)

\subsection{Composites obtaining and characterization}

The fibres were cut to around $2 \mathrm{~mm}$ length and blended with polyethylene (PE), from Matrix Polymers (Matrix Revolve N-461); composites were produced at 10, 20, 30 and $40 \%$ (in weight) of agave fibres, by compression moulding of the PE/fibres in an aluminium mould to produce square flat plates of $190 \times 190 \mathrm{~mm}$ and $3 \mathrm{~mm}$ thickness; composites were produced in a Collin P200 PM hot press, with plates temperature of $180^{\circ} \mathrm{C}$ and pressure of 35 bar. The composite plates were machined to obtain test bars with the shape and dimensions defined in UNE-EN ISO 3167, type A for tensile tests, UNE-EN ISO 178 for flexural tests, UNE-EN ISO 180 for Izod impact tests), as shown in Fig. 3.

Composites were tested to determine their mechanical behaviour, by flexural, tensile and impact tests. Flexural tests were performed under the recommendations established in UNE-EN ISO 178:2011, while tensile tests followed standard UNE-EN ISO 527-2:2012, both at a test rate of $10 \mathrm{~mm} / \mathrm{min}$ and a reading frequency of $0.1 \mathrm{~s}$ from Dongguan Liyi Test Equipment (model LY-1065). Impact tests were performed following UNE-EN ISO 180:2001/ A2:2013, using unscaled test bars, with a $5.5 \mathrm{~J}$ pendulum and impact speed of $3.5 \mathrm{~m} / \mathrm{s}$ in a Dongguan Liyi Test Equipment (model LY-XJJD 50) device. Tests were performed at room temperature $\left(22{ }^{\circ} \mathrm{C}\right)$ and $65 \%$ humidity. Results shown in Sect. 3.3 are the average values of 5 specimens tested, for each type of assay (that is, 15 samples were machined for the different mechanical tests). Figure 4 shows some pictures of the obtained composites, and a backlight picture taken for a plate with $10 \%$ of fibre, where a good homogeneity of the fibres within the entire part can be observed.

\section{Results and discussion}

\subsection{Plant characterization}

The characterization studies have been performed separating the leaves in different parts: pulp (internal white part of the plant), skin (outer layer, hard, where most of
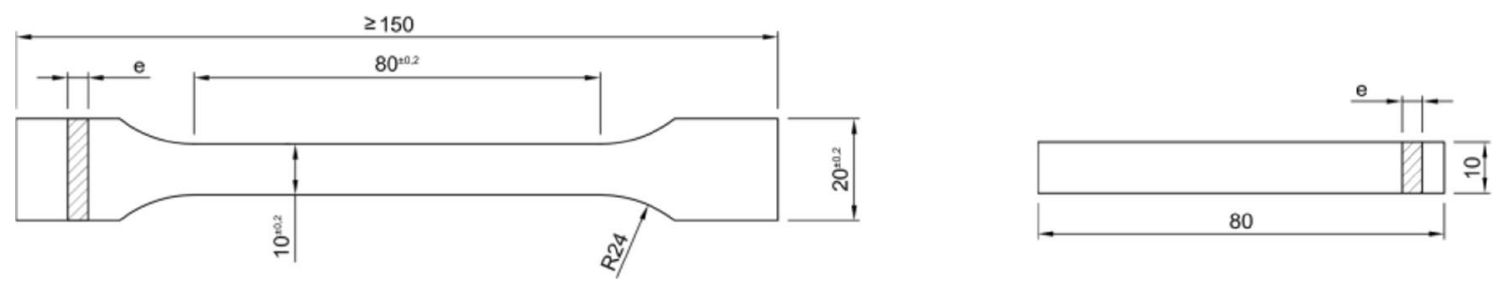

Fig. 3 Dimensions of test bars for tensile (left), flexural and impact tests (right) 

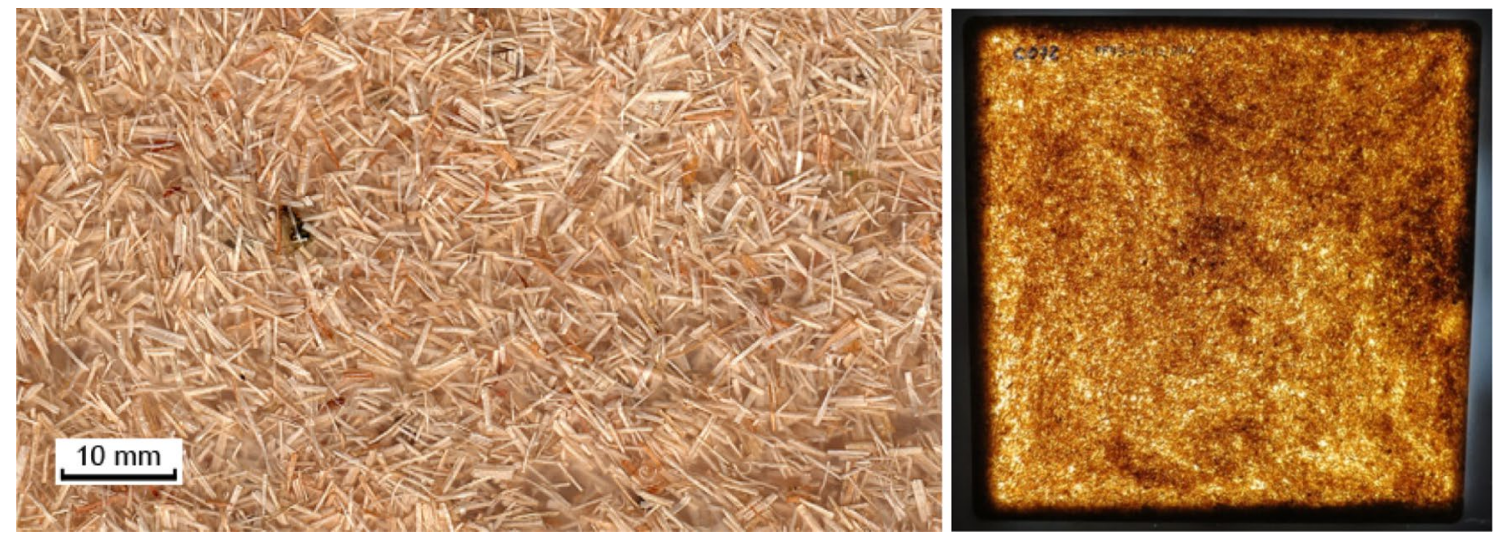

Fig. 4 Composites obtained with untreated Agave americana L. fibres at 30\% (left). Plate with 10\% of fibre, showing fibres distribution in the matrix (right)

Table 1 Chemical composition obtained for Agave americana L. plant

\begin{tabular}{lrll}
\hline $\begin{array}{l}\text { Section of the } \\
\text { plant }\end{array}$ & Lignin (\%) & \multicolumn{2}{l}{ Holocellulose (\%) } \\
\cline { 2 - 4 } & & Cellulose (\%) & Hemicellulose (\%) \\
\hline Pulp & $6.81 \pm 1.71$ & $34.34 \pm 9.59$ & \\
Skin & $10.64 \pm 4.85$ & $47.78 \pm 9.66$ & \\
Entire leaves & $10.11 \pm 1.87$ & $49.39 \pm 3.76$ & \\
Fibres & $5.88 \pm 0.22$ & $61.04 \pm 1.21$ & $22.79 \pm 1.88$ \\
Treated fibres & $4.47 \pm 0.91$ & $78.92 \pm 1.10$ & $11.41 \pm 0.89$ \\
\hline
\end{tabular}

fibres are found) and entire leaves; Klason lignin and holocellulose content based on acid hydrolysis are summarized in Table 1.

The low content in holocellulose can be explained by the high level of extractives found in the Agave americana L. leaves (up to $80 \%$ for the dry pulp); most part of these extractives is composed of carbohydrates, being sugars the most part of these extractives (results not shown). Humidity in the plant has been established around $86.5 \pm 5.1 \%$ in this study, while other authors have found up to $87 \%$ of water content in the plant [28].

It can be observed that the outer skin shows higher content in lignin and in holocellulose than pulp. Singha an Rana obtained lower contents [29] of lignin for agave leaves (1.9\%), similar values for holocellulose $(42.9 \%)$ and an important ratio $(47.6 \%)$ of monosaccharides (being glucose the most important one). Some significant differences were observed in the results obtained from the several samples analysed. For example, holocellulose content varies from 20 to $40 \%$ for the pulp, while lignin content is found to be $5-10 \%$. These differences have also been found in the literature for proximal analysis; for example Corbin [28] obtained $40 \%$ of soluble sugars and $6.2 \%$ of proteins, while Bouaziz and collaborators [30] found $20 \%$ of sugars and $29 \%$ of proteins; besides, Li obtained differences up to $8 \%$ in cellulose content in two different leaves from the same plant [31]. These differences are due to the high dependency of the plant composition and characteristics with the age of the plant, age of the leaf, climate conditions, region, etc.

Extraction assays have led to the obtaining of a $5.9 \pm 1.4 \%$ of fibre (on the basis of dry leaves). Other authors have found a fibre content around $4 \%$ for sisal leaves $[32,33]$.

\subsection{Fibre characterization}

Results in Table 1 show that the chemical composition obtained for agave fibres extracted in this research by mechanical procedures is quite similar to the one obtained by other authors; for example, Mylsami and Rajendran [34] obtained $4.85 \%$ of lignin, $15.67 \%$ of hemicellulose and $68.42 \%$ of cellulose, while El Oudiani [26] found lower values for lignin (2.72\%) and higher for hemicellulose (32.07\%), with similar values for cellulose (65.19\%). This composition is also quite close to the obtained for sisal and other commercial fibres, such as jute, hemp or flax [20], in which cellulose content reaches up to $90 \%$.

On the other hand, as expected, treated agave fibres show a reduction in hemicellulose content to almost half of the original content, also with a slight reduction in lignin; this leads to the increase in cellulose content, reaching almost $80 \%$ of the fibre. This same behaviour is found in the literature, with cellulose ratios in $\mathrm{NaOH}$ treated fibres reaching over $85 \%[19,27]$. It is also interesting to take into account that alkali treatment can transform crystallinity of the cellulose in the fibres, and also the type of cellulose found; El Oudiani found the highest crystallinity for $2 \% \mathrm{NaOH}$ - treated fibres, while the highest shift from cellulose I to cellulose II happened for $10-15 \% \mathrm{NaOH}$ 
solutions, leading higher concentrations to cellulose degradation [35].

Degradation temperature for fibres is around $210^{\circ} \mathrm{C}$ (left limit temperature, onset is $290^{\circ} \mathrm{C}$ ), which is quite close to the degradation temperatures of jute $\left(205^{\circ} \mathrm{C}\right)$ [36], widely used in the composites industry. Other authors have found a left limit temperature for Agave fibres of $240.15^{\circ} \mathrm{C}$ [37], and onset temperatures of $272^{\circ} \mathrm{C}$ [14]. Figure 5 shows the thermogravimetric curves for treated and untreated fibres, where it can be observed that treated fibres show higher thermal stability than untreated ones; left limit temperature increases up to $230^{\circ} \mathrm{C}$ due to the alkali treatment, while onset temperature removes unchanged. Besides, the derivative curve also shows that the shoulder found around $300{ }^{\circ} \mathrm{C}$ for untreated fibres disappears for the treated one, due to the reduction in the hemicellulose content, as also found in the literature [14]. The highest peak found in this curve, for around $349^{\circ} \mathrm{C}$ for untreated fibres and $322^{\circ} \mathrm{C}$ for treated ones, is due to the degradation of a-cellulose, and can also be observed for other agave fibres [14, 32].

The lower weight loss in the range between 220 and $278{ }^{\circ} \mathrm{C}$ ( $8.9 \%$ for virgin fibres and $2.6 \%$ for treated ones) is related also to the lower hemicellulose content due to its solubilisation during the alkaline treatment. Finally, it can also be stated that treated fibres have lower hydrophilicity than untreated ones, as weight loss at $105^{\circ} \mathrm{C}$ is smaller for treated fibres.

When observing the FTIR spectra, the low content in lignin for fibres is clear, as the peak around has low intensity for untreated fibres and disappears for treated ones (Fig. 6).

Main differences found due to the fibres treatment, apart from the disappearance of the lignin related peak, are the higher intensities found at $1412 \mathrm{~cm}^{-1}$, which is attributed to the appearance of sodium carboxylates $(\mathrm{R}-\mathrm{C}=\mathrm{O}-\mathrm{ONa})$ [38]. The higher importance of the peak at $2900 \mathrm{~cm}^{-1}$, related to the presence of cellulose and hemicellulose ( $\mathrm{C}-\mathrm{H}$ links), can be explained by the surface modification of the fibres due to the chemical treatment. Finally, the shoulder at $1100 \mathrm{~cm}^{-1}$, usually linked to hemicellulose, disappears for treated fibres, which also suggests the reduction in the hemicellulose content of fibres as a consequence of the alkaline treatment.

From FTIR spectra, some data related to crystallinity of cellulose in the fibres can be obtained (Table 2), as explained by El Oudiani et al. [39]. The Total Crystallinity Index (TCl) is obtained by dividing the absorbance at $1375 \mathrm{~cm}^{-1}$ by that at $2900 \mathrm{~cm}^{-1}$, and the value obtained is proportional to the degree of crystallinity of the cellulose in the fibres. Results seems to indicate that treated samples have higher levels of crystallinity, as TCI is higher; results are close to those obtained by Bezazi and collaborators, appearing that fibres extracted by mechanical means have higher crystallinity, although are quite far from results reported by El Oudiani and co-authors for agave fibres [39]. In this same paper, values reported for other fibres, such as sisal, are higher, reaching up to 1.300 . It would be interesting to have a clearer idea about the type of cellulose found in these fibres and its crystallinity level, but a different set of techniques would be more appropriate for this.

\subsection{Composites characterization}

As shown in Fig. 7, flexural properties are increased with the introduction of the fibres in the PE matrix, while for tensile tests, only elastic modulus rises due to the introduction of fibres. Specifically, the introduction of a $40 \%$ of untreated agave fibres increases a $50 \%$ the tensile
Fig. 5 TGA and DTGA curves for treated and untreated agave fibres

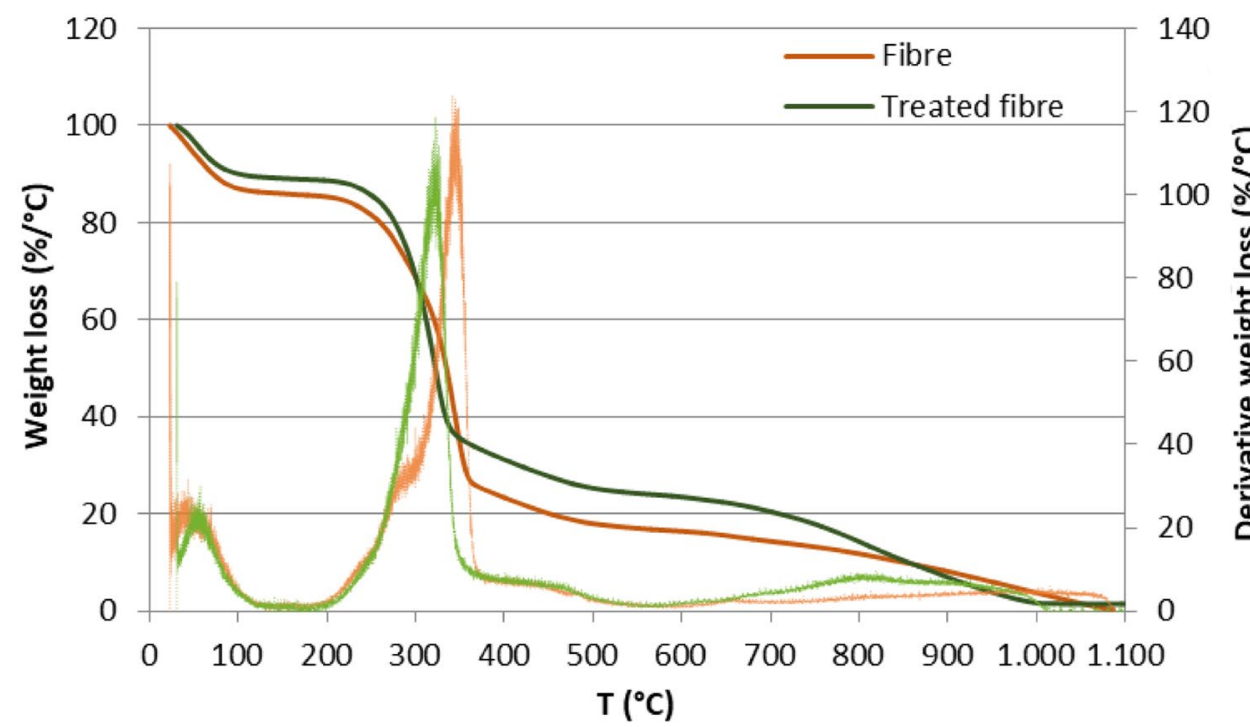

SN Applied Sciences 
Fig. 6 FTIR spectra for agave fibres

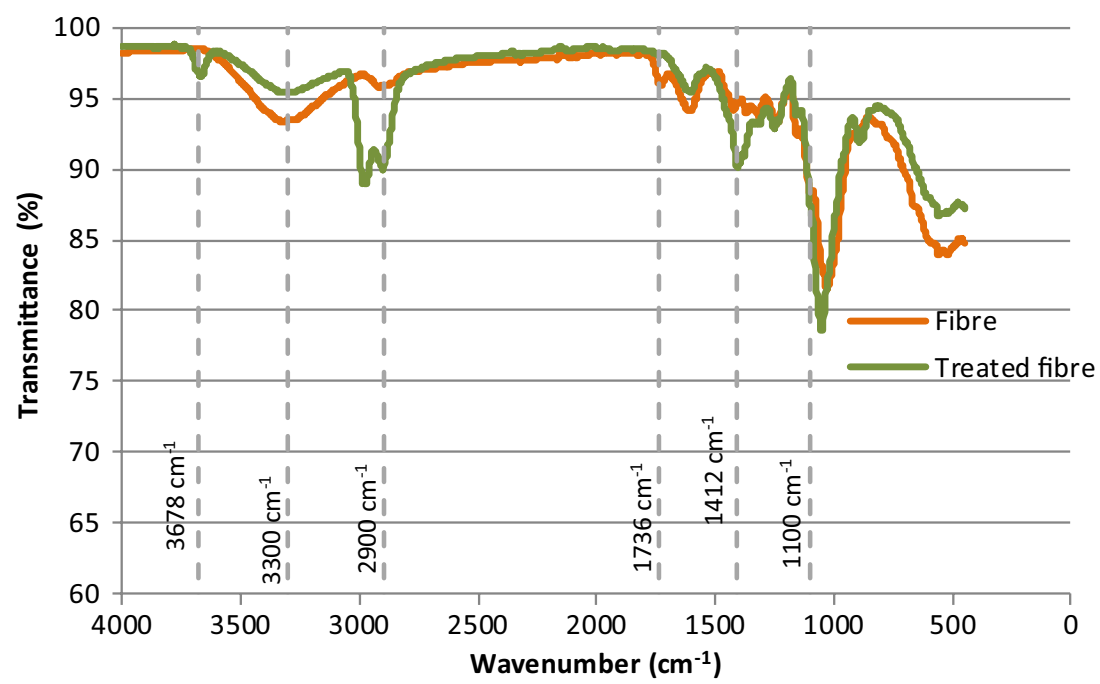

Table 2 Results obtained for Agave americana L. plant

\begin{tabular}{lll}
\hline Sample & $\mathrm{TCl}\left(\mathrm{I}_{1372} / \mathrm{I}_{2900}\right)$ & References \\
\hline Agave americana L. fibres & 0.983 & -- \\
Treated Agave americana L. fibres & 1.009 & -- \\
Agave americana L. fibres & 0.660 & {$[39]$} \\
Water retted Agave americana L. fibres & 0.903 & {$[32]$} \\
$\begin{array}{l}\text { Earth-buried Agave americana L. } \\
\text { fibres }\end{array}$ & 0.924 & \\
\hline
\end{tabular}

elastic modulus (from $600 \mathrm{MPa}$ for net PE to $900 \mathrm{MPa}$ for the composite), while flexural properties are improved around $17 \%$ for maximum strength (from around $19 \mathrm{MPa}$ for PE to $23 \mathrm{MPa}$ for the composite) and the performance is over the double for the elastic modulus (628 MPa for $\mathrm{PE}$ and $1651 \mathrm{MPa}$ for the $40 \%$ composite); in counterpart, maximum tensile strength for this composite is reduced by $36 \%$. Also for this composite, elastic limit is almost doubled for tensile tests and is increased by $32 \%$ for flexural ones.

On the other hand, although flexural properties show an improvement due to fibre use and tensile properties are not negatively affected to high extent, impact resistance is strongly reduced (up to $50 \%$ ) for the composites containing $40 \%$ of untreated fibres (Fig. 8). Composites with treated fibres show lower reduction in this case. Other authors have found that alkali treated fibres provide better mechanical properties, mainly in impact and flexural tests, although in an epoxy resin matrix [13,34].

The use of agave fibres in a polystyrene matrix have shown an increase in the tensile strength up to $25 \%$ for a $20 \%$ composite, while higher ratios of fibres implies a reduction in mechanical properties [40]. Singha and collaborators [37] found an increase in mechanical properties, mainly in impact behaviour, for composites up to $30 \%$ of agave fibres, also using polystyrene as matrix; they have also demonstrated that the size of the is an important
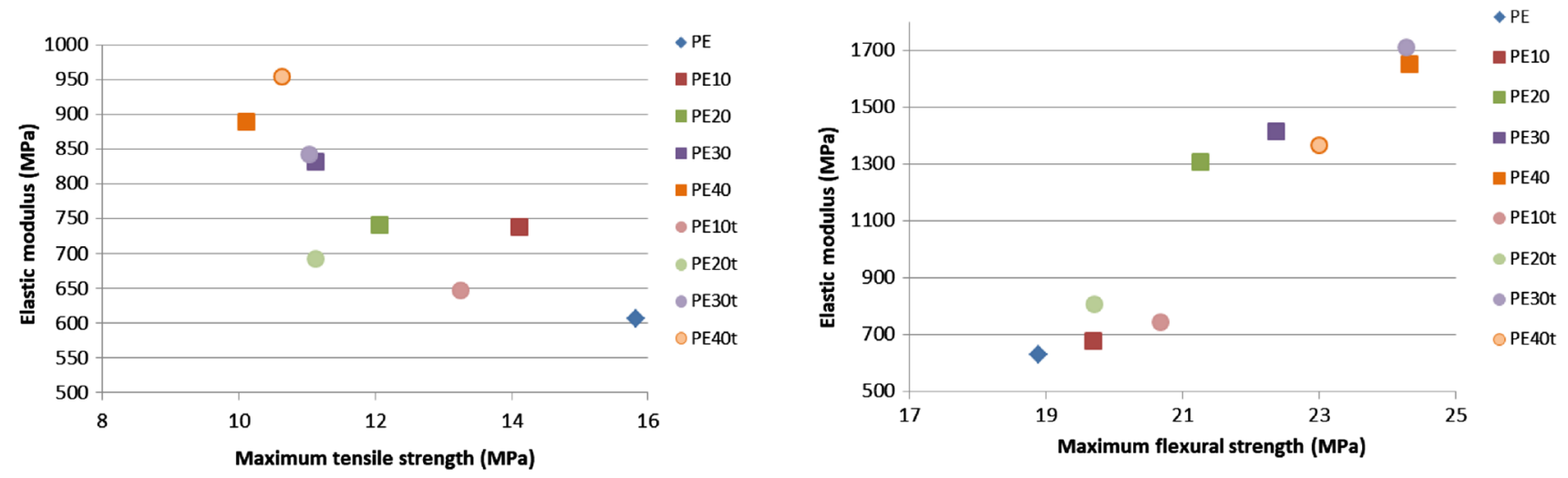

Fig. 7 Mechanical properties obtained at tensile (left) and flexural (right) tests 
Fig. 8 Impact properties obtained for the 9 formulations

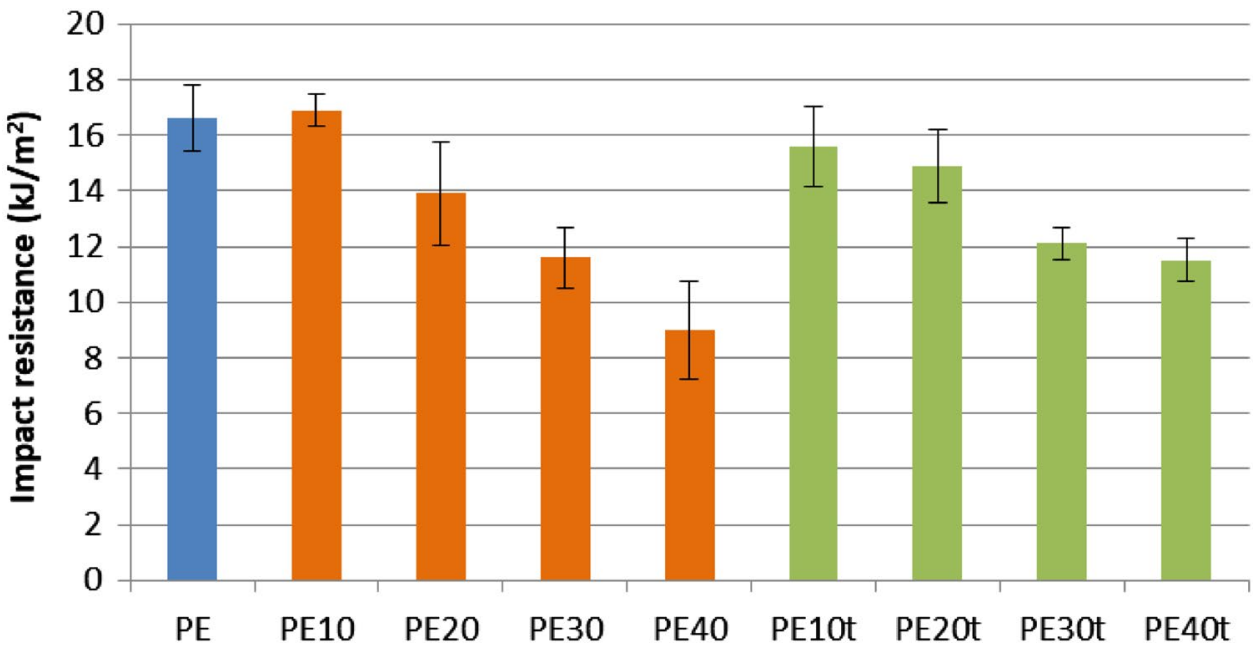

factor to take into account. Other authors, working with Agave tequilana fibres [33], also found that, for compression moulding and PP composites, $30 \%$ of fibre provides the best mechanical results. Cisneros-López and collaborators [41] found that rotationally moulded PLA composites with $10 \%$ of agave fibres (agave tequilana) does not change elastic modulus, while higher fibre ratios lead to the reduction of this property; on the other hand, compression moulded PLA allowed increasing the elastic modulus of net PLA by a $14 \%$ for $30 \%$ composites, while $40 \%$ fibre composites had an elastic modulus 13\% lower. These authors obtained also similar results for flexural properties, that is, mechanical properties remained unchanged for $10 \%$ composites, while drastic reductions were observed for $40 \%$ composites. Langhost [42] obtained an increase in the flexural properties for injected PP composites with up to $30 \%$ of agave fibres (agave tequilana), while a reduction in tensile and impact strength were observed. These authors also found that the use of a compatibilizer, such as grafted PP with maleic anhydride, increases the mechanical properties of the composite.
Finally, as observed in Table 3, even if some mechanical features are reduced due to the incorporation of natural fibres in the PE matrix, if specific properties are considered, these reductions can be neglected in many cases, while improvements are still more significant. It is particularly interesting to take a look on the composites with $40 \%$ of fibres, which show a great increase in flexural properties (modulus is almost three times higher than for the PE matrix); the influence of the fibre treatment is clearly observed here, with an increase of the impact properties of the treated fibre composite compared with the untreated ones. It is well known that this is one of the most attractive properties of natural fibres [20], which is here also put in value.

\section{Conclusions}

- Composition of Agave americana fibres is similar to those shown by other cellulosic fibres, as well as their FTIR spectra and thermal behaviour.
Table 3 Changes in specific mechanical properties (\%) respect to $P E$ results for the different composites

\begin{tabular}{|c|c|c|c|c|c|}
\hline \multirow[t]{2}{*}{ Composite } & \multicolumn{2}{|c|}{ Tensile properties } & \multicolumn{2}{|c|}{ Flexural properties } & \multirow{2}{*}{$\begin{array}{l}\text { Impact properties } \\
\text { Resistance }\end{array}$} \\
\hline & Modulus (\%) & $\begin{array}{l}\text { Maximum } \\
\text { strength }\end{array}$ & Modulus & $\begin{array}{l}\text { Maximum } \\
\text { strength }\end{array}$ & \\
\hline PE & 0.0 & 0.0 & 0.0 & 0.0 & 0.0 \\
\hline PE10 & 30.6 & -4.5 & 15.9 & 11.6 & 9.0 \\
\hline PE20 & 32.0 & -17.7 & 124.8 & 21.5 & -9.7 \\
\hline PE30 & 50.3 & -23.1 & 146.3 & 29.7 & -23.5 \\
\hline PE40 & 61.8 & -29.6 & 189.7 & 42.0 & -40.3 \\
\hline PE10t & 12.5 & -11.9 & 24.8 & 15.2 & -1.1 \\
\hline PE20t & 21.1 & -25.6 & 36.0 & 10.5 & -5.0 \\
\hline PE30t & 51.5 & -24.1 & 196.7 & 40.0 & -20.7 \\
\hline PE40t & 69.7 & -27.6 & 134.8 & 31.3 & -25.4 \\
\hline
\end{tabular}


- Thermal stability increases with $\mathrm{NaOH}$ treatment, as shown by the increased left limit temperature shown by treated fibres. Also, cellulose content is increased from around 60 to almost $80 \%$, as a consequence, mainly, of hemicellulose removal.

- The introduction of agave fibres in the polyethylene matrix has been successfully achieved, reaching up to a $40 \%$ in weight. These composites show an improvement in tensile elastic modulus and in flexural properties, although with a slight decrease in maximum tensile strength and impact properties.

- Composites with treated fibres show similar behaviour to those containing untreated fibres, being impact and flexural properties the most influenced by the fibres treatment.

- Mechanical specific properties are greatly increased by the use of Agave americana L. fibres, mainly those under flexural tests. Impact properties are reduced, as expected, although the fibre treatment can help to reduce this drop.

- Agave americana L. has shown a great potential to be used as reinforcement in polymer composites. The usage of these invasive plants provides an added value to the use of natural sourced materials, as a strategy for the control (or eradication in the best of cases) of these species could be outlined, giving a final use to the wastes produced in these campaigns.

Acknowledgements The authors gratefully acknowledge the funding by European Funding for Regional Development (FEDER), INTERREG V-A MAC 2014-2020 [MAC ECOFIBRAS, Grant Number MAC/4.6d/040].

\section{Compliance with ethical standards}

Conflict of interest The authors declare that they have no conflict of interest.

\section{References}

1. Ministerio para la Transición Ecológica (2004) Catálogo español de especies exóticas invasoras. Ministerio para la Transición Ecológica, Madrid, pp 1-4

2. Bionatura I Agave americana L. Pitera común. http://www. interreg-bionatura.com/especies/pdf/Agave americana.pdf. Accessed 7 July 2019

3. Lowe S, Browne M, Boudjelas S, De Poorter M (2004) 100 of the World's worst invasive alien species-a selection from the global invasive species database. http://www.iucngisd.org/gisd/ pdf/100Spanish.pdf. Accessed 7 July 2019

4. Global Industry Trends Report (2018) Natural fibers market analysis, market size, application analysis, regional outlook, competitive strategies and segment forecasts, 2018 to 2025

5. Townsend T, Sette J (2015) Natural fibres and the world economy. Discover Natural Fibres. http://www.dnfi.org/abaca/natur al-fibres-and-the-worldeconomy_1778/. Accessed 7 July 2019
6. Karus M, Kaup M, Lohmeyer D (2000) Study on markets and prices for natural fibres (Germany and EU). Nova Institute. http:// www.nova-institut.de/pdf/nova-study-full.pdf. Accessed 7 July 2019

7. Ministerio de Agricultura Alimentación y Medioambiente (2013) Catálogo español de especies exóticas invasoras-Agave americana L. Ministerio de Agricultura Alimentación y Medioambiente, Madrid

8. Sidana J, Singh B, Sharma OP (2016) Saponins of Agave: chemistry and bioactivity. Phytochemistry 130:22-46

9. Yang Q, Pan X (2012) Pretreatment of Agave americana stalk for enzymatic saccharification. Biores Technol 126:336-340

10. Nasri S, Ben Salem H (2012) Effect of oral administration of Agave americana or Quillaja saponaria extracts on digestion and growth of Barbarine female lamb. Livest Sci 147(1-3):59-65

11. Yang L et al (2015) Biomass characterization of Agave and Opuntia as potential biofuel feedstocks. Biomass Bioenergy 76:43-53

12. Geethika VN, Rao VDP (2017) Study of tensile strength of Agave Americana fibre reinforced hybrid composites. Mater Today Proc 4(8):7760-7769

13. Mylsamy K, Rajendran I (2011) The mechanical properties, deformation and thermomechanical properties of alkali treated and untreated Agave continuous fibre reinforced epoxy composites. Mater Des 32(5):3076-3084

14. Thamae T, Baillie C (2007) Influence of fibre extraction method, alkali and silane treatment on the interface of Agave americana waste HDPE composites as possible roof ceilings in Lesotho. Compos Interfaces 14(7-9):821-836

15. Bezazi A, Belaadi A, Bourchak M, Scarpa F, Boba K (2014) Novel extraction techniques, chemical and mechanical characterisation of Agave americana L. natural fibres. Compos Part B Eng 66:194-203

16. Bessadok A, Langevin D, Gouanvé F, Chappey C, Roudesli S, Marais S (2009) Study of water sorption on modified Agave fibres. Carbohydr Polym 76(1):74-85

17. Bessadok A, Marais S, Roudesli S, Lixon C, Métayer M (2008) Influence of chemical modifications on water-sorption and mechanical properties of Agave fibres. Compos Part A Appl Sci Manuf 39(1):29-45

18. Chaabouni Y, Drean JY, Msahli S, Sakli F (2006) Morphological characterization of individual fiber of Agave americana L. Text Res J 76(5):367-374

19. Saraswat BK, Gope PC (2017) Effects of alkali treatment on Agave americana fibre properties. Int J Eng Technol 5(6):2349-4476

20. Satyanarayana KG, Guimarães JL, Wypych F (2007) Studies on lignocellulosic fibers of Brazil. Part I: source, production, morphology, properties and applications. Compos Part A Appl Sci Manuf 38(7):1694-1709

21. Msahli S, Jaouadi M, Sakli F, Drean J-YY (2015) Study of the mechanical properties of fibers extracted from Tunisian Agave americana L. J Nat Fibers 12(6):552-560

22. Kestur S, Flores-Sahagun THS, Dos Santos LP, Dos Santos J, Mazzaro I, Mikowski A (2013) Characterization of blue agave bagasse fibers of Mexico. Compos Part A Appl Sci Manuf 45:153-161

23. 1977a Standard test methods for lignin in wood-D 1106-56. 1977a, Washington DC

24. Browing BL (1967) Methods of wood chemistry. Polym Phys 6(11):1943-1944

25. Mylsamy K, Rajendran I (2011) Influence of alkali treatment and fibre length on mechanical properties of short Agave fibre reinforced epoxy composites. Mater Des 32(8-9):4629-4640

26. El Oudiani A, Ben Sghaier R, Chaabouni Y, Msahli S, Sakli F (2012) Physico-chemical and mechanical characterization of alkalitreated Agave americana L. fiber. J Text Inst 103(4):349-355

27. Jain D, Kamboj I, Bera TK, Kang AS, Singla RK (2019) Experimental and numerical investigations on the effect of alkaline 
hornification on the hydrothermal ageing of Agave natural fiber composites. Int J Heat Mass Transf 130:431-439

28. Corbin KR et al (2015) Prospecting for energy-rich renewable raw materials: agave leaf case study. PLoS ONE 10(8):e0135382

29. Singha AS, Rana RK (2012) Natural fiber reinforced polystyrene composites: effect of fiber loading, fiber dimensions and surface modification on mechanical properties. Mater Des 41:289-297

30. Bouaziz A, Masmoudi M, Kamoun A, Besbes S (2014) Optimization of insoluble and soluble fibres extraction from Agave americana L. Using Response surface methodology. J Chem 2014:1-13

31. Li H et al (2012) Chemical composition and characterization of cellulose for Agave as a fast-growing, drought-tolerant biofuels feedstock. RSC Adv 2(11):4951

32. Belaadi A, Bezazi A, Bourchak M, Scarpa F, Zhu C (2014) Thermochemical and statistical mechanical properties of natural sisal fibres. Compos Part B Eng 67:481-489

33. Sahu P, Gupta MK (2017) Sisal (Agave sisalana) fibre and its polymer-based composites: a review on current developments. J Reinf Plast Compos 36(24):1759-1780

34. Mylsamy K, Rajendran I (2011) Influence of alkali treatment and fibre length on mechanical properties of short Agave fibre reinforced epoxy composites. Mater Des 32(8-9):4629-4640

35. ElOudiani A, Chaabouni Y, Msahli S, Sakli F (2011) Crystal transition from cellulose i to cellulose II in $\mathrm{NaOH}$ treated Agave americana L. fibre. Carbohydr Polym 86(3):1221-1229

36. De Rosa IM, Kenny JM, Puglia D, Santulli C, Sarasini F (2010) Morphological, thermal and mechanical characterization of okra (Abelmoschus esculentus) fibres as potential reinforcement in polymer composites. Compos Sci Technol 70(1):116-122
37. Singha AS, Rana RK (2012) Natural fiber reinforced polystyrene composites: effect of fiber loading, fiber dimensions and surface modification on mechanical properties. Mater Des 41:289-297

38. Guzmán RE, Gómez S, Amelines O, Aparicio GM (2018) Superficial modification by alkalization of cellulose Fibres obtained from Fique leaf. In: IOP conference series: materials science and engineering, vol 437, no 1

39. El Oudiani A, Msahli S, Sakli F (2017) In-depth study of agave fiber structure using Fourier transform infrared spectroscopy. Carbohydr Polym 164:242-248

40. Hernández-Hernández HMM et al (2016) Acetosolv treatment of fibers from waste agave leaves: influence of process variables and microstructural study. Ind Crops Prod 86:163-172

41. Cisneros-López EO et al (2018) Polylactic acid-agave fiber biocomposites produced by rotational molding: a comparative study with compression molding. Adv Polym Technol 37(7):2528-2540

42. Langhorst $A E$, Burkholder J, Long J, Thomas R, Kiziltas A, Mielewski D (2018) Blue-agave fiber-reinforced polypropylene composites for automotive applications. BioResources 13(1):820-835

Publisher's Note Springer Nature remains neutral with regard to jurisdictional claims in published maps and institutional affiliations. 